\title{
建筑工程项目施工现场的合同管理与索赔
}

\author{
石唯永* \\ 陕西西咸新区秦汉房地产开发有限公司 陕西 咸阳 712000
}

摘 要: 随着我国建筑行业的快速发展, 索赔等合同纠纷越来越多。合同是业主与施工方的利益体现。随着当前 市场的竞争越发得激烈，企业想要得到好的效益，做好合同管理及索赔工作非常的重要。因此，施工单位一定要做好 合同的管理及相关的索赔工作，要具备一定的超前意识和风险意识。当出现合同纠纷的时候，要通过法律的手段来维 护企业合法的利益。本文就以建筑工程项目施工现场的合同管理与索赔为研究内容, 并展开相关的讨论。

关键词：建筑工程; 施工现场; 合同管理与索赔

DOI: https://doi.org/10.37155/2661-4669-0309-32

\section{Contract Management and Claim on Construction Site of Construction Project}

\author{
Wei-Yong Shi* \\ Shaanxi Xixian New Area Qinhan Real Estate Development Co., Ltd., Xianyang 712000, Shaanxi, China
}

\begin{abstract}
With the rapid development of China's construction industry, there are more and more contract disputes such as claims. The contract is the embodiment of the interests of the owner and the construction party. With the increasingly fierce competition in the current market, it is very important for enterprises to do a good job in contract management and claim if they want to get good benefits. Therefore, the construction unit must do a good job in contract management and related claim work, and have a certain sense of advance and risk. When contract disputes arise, legal means should be used to safeguard the legitimate interests of enterprises. This paper takes the contract management and claim of construction project construction site as the research content, and carries out relevant discussions.
\end{abstract}

Keywords: Architectural engineering; Construction site; Contract management and claims

引言

从建筑工程施工单位的角度来看, 项目施工现场的合同管理和索赔是非常重要 ${ }^{[1]}$ 。因此施工企业要从工程的实际 出发，不断地提高合同管理的质量，降低索赔的概率，确保工程的顺利开展。

\section{1 施工现场合同管理的内容}

1.1 合同管理的含义

建筑工程项目施工现场合同管理与索赔，主要指的是施工企业与建设单位之间实现工程建设的目的和自身的经济利 益, 双方需要明确职责与义务的书面协议。科学合理地做好合同管理和索赔工作, 是保障工程项目利益的重要方法。

1.2 合同管理的职能

在建筑工程项目当中，合同中确定了工程的造价、施工质量要求、施工最终目的等，施工单位及业主要明确地在 合同内容中提出双方的责任和义务。合同管理及索赔工作贯穿整个建筑工程的施工，对工程的质量有着重要的管控和 保障的作用 ${ }^{[2]}$ 。如果建筑工程施工过程中无法保障合同的管理工作，势必会影响施工现场的管理工作。随着我国建筑 行业的不断发展, 对于合同管理的要求也越来越高, 不仅需要设立专职管理人员, 还需要相关人员掌握一定的专业知 识 ${ }^{[3]}$ 。由此可见合同管理与索赔在建设工程施工过程中发挥着重要的作用。

*通讯作者：石唯永，男，汉族，1987.5.18，陕西西安，本科，中级工程师，研究方向：工程管理。 


\section{2 发生合同索赔的主要原因分析}

2.1 建筑工程的特点

建筑工程项目最显著的特点就是规模大，占用资金比较的多，且施工周期都比较长。在工程规划的初期，要进行 招标等前期工作，这些工作需要大量的资金投人，在施工过程也会消耗大量的资金，这一过程中涉及到的材料设备等 都会随着市场价格的变化产生价格波动，在施工过程中还会出现一些客观原因等，例如：天气灾害等，都会对建筑工 程的施工成本产生一定的影响, 这就需要综合考虑, 结合实际情况, 来科学合理的拟定合同条款。材料价格走势图如 图1所示。

\section{CRU 长材和板材价格指数走势图}

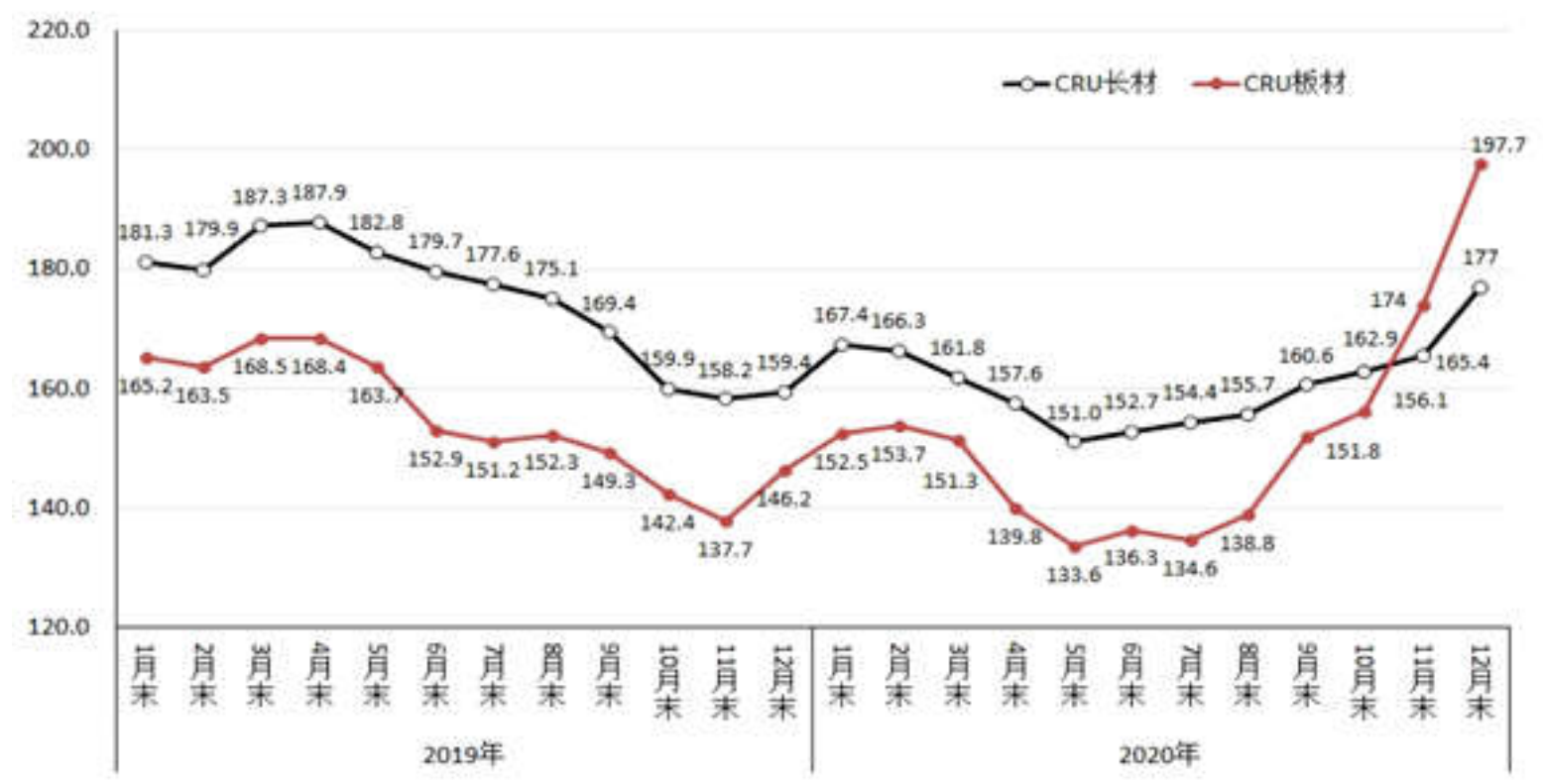

图1 材料价格走势图

2.2 建筑工程施工图纸出现设计失误（此论点下论据能否再丰富下）?

合同对建筑工程项目的施工和管理有着重要的监督管理作用，在合同管理工作中，最常遇到的就是图纸施工出现 设计上的失误，导致双方签订的合同不具有合法性 ${ }^{[4]}$ ，也会对合同上施工图纸的真实性和可靠性产生怀疑。在这一过 程中, 很有可能导致双方出现一些矛盾, 施工现场管理混乱, 施工进度受损，不但会对双方的职责产生一定的问题， 还会对施工企业造成一定的经济损失，有的甚至需要延长施工周期，就此引发合同索赔。

\section{3 建筑工程合同管理现状}

3.1 合同管理工作存在不规范现象

建筑工程施工企业在施工过程中，不能对合同管理工作做到正确的认识。合同管理工作在建筑工程过程中发挥着 重要的作用, 如果不能做好合同管理工作, 很有可能会对企业造成极大的损失 ${ }^{\left[{ }^{[}\right]}$。例如: 未能及时地发现合同当中涉 及敏感话题的条款，导致双方在签订合同之后出现纠纷，无法利用法律手段来保护企业自身的利益。

3.2 缺乏合同管理意识

在建筑工程施工过程当中，许多合同管理人员没有意识到合同管理工作的重要性。这个想法是错误的，甚至会给 企业带来经济损失。施工企业要给负责合同管理的工作人员树立正确的合同管理理念，保障施工企业及业主双方的利 益, 避免发生纠纷。合同管理流程如图2所示。 


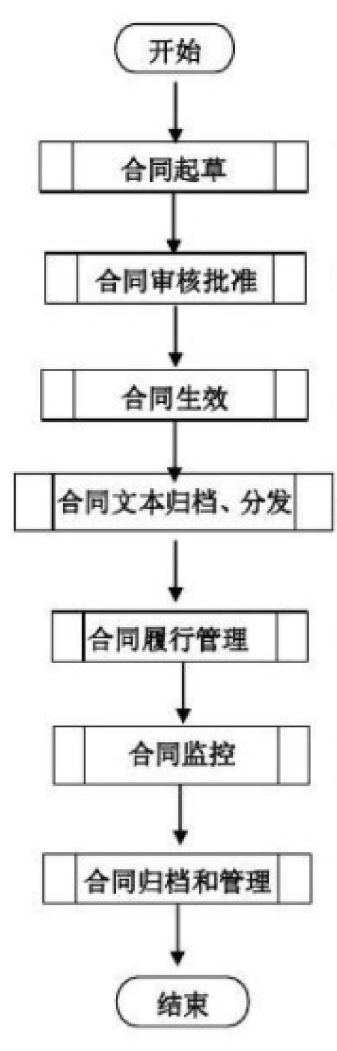

3.3 合同管理工作缺乏专业人才

图2 合同管理流程

在建筑工程项目施工过程中，许多项目经理对索赔工作不够重视，认为把控成本的关键是价格，从而拿个合同之 后不对合同的内容进行仔细地研究。合同管理的相关工作人员也没有正确的认识到施工过程中存在的各种风险, 没有 正确的避开风险，导致了出现风险之后无法第一时间减少损失，且合同管理人员不具备相关的专业知识，导致索赔工 作开展得不够顺利 ${ }^{[6]}$ 。造成更大的损失。

\section{4 做好建筑工程项目的合同管理与索赔工作}

合同管理工作与索赔这两项工作之间有着密不可分的关系，合同管理是索赔的重要依据。索赔主要指的是出现不 完全履行合同内容或违反合同约定给施工单位造成了一定的经济损失, 索要赔偿的一种行为。想要索赔成功, 就要从 以下四个方面做起。

\section{1 获取并收集索赔证据}

索赔作为一项解决纠纷的特殊方法, 是施工企业维护自身合法权益的重要手段。想要做好索赔工作, 首先要收集 好相关的证据, 如果出现证据不足或其他情况, 索赔是无法成功的, 且索赔的许多证据是在建筑工程施工过程中产生 的, 这就需要我们在日常的工作中做好证据的收集。当企业需要进行索赔时, 合同管理人员要第一时间进行证据的收 集，这是索赔过程中的关键工作。收集到的证据要确保全面且真实有效。

4.2 研究合同当中的条款, 做好索赔工作

对合同的内容及条款进行研究，具体指的是对合同当中所约定的条款进行全方位的分析的一个过程，通过分析合 同的条款，可以有效地帮助施工单位更好的明确自身的权利和义务，以便更有针对性地做好相关索赔的工作。

作为合同管理的工作人员，在施工单位进行施工的过程中，要结合相关的法律法规，对合同进行认真地研究，最 大限度的确保施工单位自身的经济利益。合同不仅仅是重要的法律依据, 同时也是帮助施工单位实现利益的重要手 段。合同当中除了明确规定的一些条款之外，还有许多暗含的隐藏索赔因素，这些都需要合同管理人员对合同进行一 定的研究才能做好相关工作。 


\section{3 加强合同管理工作}

引发索赔的因素会对施工现场带来一定的经济损失，这些都是建筑工程施工过程中不可避免的，因此相关工作人 员要加强合同管理工作, 对这些因素做好预判, 降低损失, 并按照相关的流程做好管理工作, 只有这样才能顺利地完 成索赔工作。

4.4 科学的索赔手段是合同索赔成功的重要因素

想要成功地获得索赔, 除了要具有专业的知识以外, 在索赔的过程中, 还需要掌握一些有效的手段和方法, 主要 有以下几点：（1）确保索赔的事实真实有效；（2）施工单位与业主的权利与义务要明确；（3）索赔内容要清晰明 了, 突出目的; (4) 索赔金额要合理, 且计算无误; (5) 适当地利用公关的方式加快索赔办理进度; (6) 设计政 策性的索赔事项一定要请求上级领导的批示，切不可私自处理。

\section{5 建立以合同管理为核心的职能部门}

项目部要建立以合同管理为主要工作的职能部门，在施工过程中，做好合同的管理工作，并且明确合同管理的流 程, 在日常工作当中, 做好合同交底, 明确各部门的职责，做好合同内容及责任的拆分。并且要掌握合同当中存在的一 些风险点, 做好风险转移工作, 出现争议之后要第一时间进行解决, 收集好证据, 做好工程的变更索赔相关工作 ${ }^{[7]}$ 。除 此之外, 项目经理部还可以定期组织变更索赔的相关会议对索赔的内容及相关事项进行研究，以确保后续的索赔工作可 以顺利推进。

\section{6 推行并实施规范的合同文本}

除了上述几点, 好的合同文本也有很强的操作性。明确合同的主体, 并参照国家的相关法律来制定合同文本，或 根据自身需要来签订合同文本。好的合同文本有利于解决施工过程当中出现的各类纠纷。

\section{5 结语}

综上所述, 在建筑工程施工过程中, 施工单位一定要建立合同管理职能部门, 在施工过程中做好合同的研究工 作，扬长避短。在签订合同的过程中，要保障合同的内容完整且考虑周全，条款含义清晰明了，这是合同的基本要 求。在施工过程中, 要严格按照合同当中的各项规定, 灵活运用条款, 及时地收集索赔相关证据, 并将证据交由业主 和监理签字审核后做好自留的保存归档, 从而形成变更索赔依据。加大合同管理工作的力度及变更索赔工作的力度, 采用科学合理的手段去完成变更索赔的工作。增强相关人员的工作意识和工作技能, 都是有效地提高建筑工程施工单 位合同管理及索赔的有效手段。

\section{参考文献:}

[1]杨雪飞.论述合同管理在建筑工程建设管理中的应用 [J].砖瓦,2021,(3):103-104.

[2]郭灵.关于我国建筑工程的经济合同管理及法律风险防范研究 [J]. 建材与装饰, 2021,17(20): 183-184.

[3]李俊杰.建筑工程项目合同预算管理与成本控制路径探究[J].砖瓦世界,2021,(13):202-203.

[4]王昌.建筑工程合同管理与造价控制的关系探析[J].建筑与装饰,2021,(2):49,55.

[5]张亮亮.建筑工程项目合同管理所涉及到的法律风险及防范措施[J].法制博览,2021,(4):171-172.

[6]陈嘉雯.浅谈建筑工程管理中合同管理的常见问题及对策 [J].建筑与装饰, 2021,(8):64.

[7]郝思齐.建筑工程合同的管理与风险防控浅析[J].价值工程,2020,39(26):16-17. 